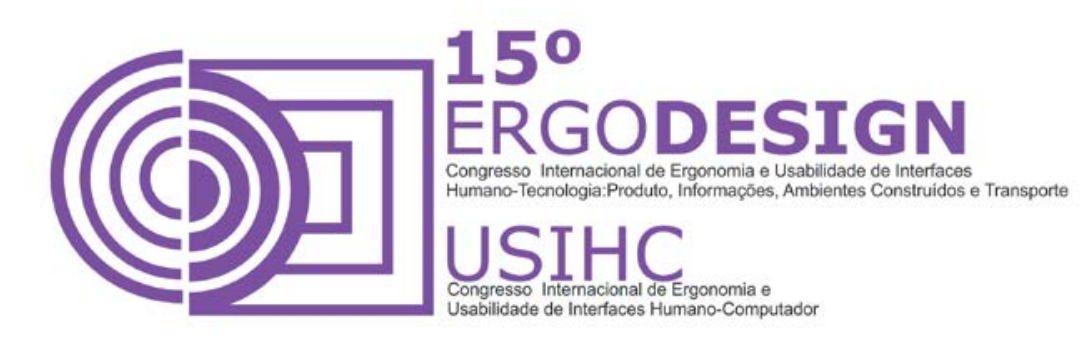

\title{
O USO DA FUNÇÃO ESTÉTICA E SIMBÓLICA NO PROCESSO DE CRIAÇÃO DE JOIAS
}

\section{THE USE OF THE AESTHETIC AND SYMBOLIC FUNCTION IN THE PROCESS OF CREATING JEWELRY}

\author{
TAKAMITSU, Helen Tatiana (1); \\ MENEZES, Marizilda dos Santos (2) \\ (1) Universidade Estadual Paulista, Mestre \\ e-mail: ht.e.ht@hotmail.com \\ (2) Universidade Estadual Paulista, Doutora \\ e-mail: marizil@faac.unesp.br
}

\begin{abstract}
RESUMO
A estética e o simbolismo representado por uma joia são fatores determinantes para a sua escolha. Este artigo tem como objetivo realizar uma análise e crítica sobre o uso destes fatores na criação de novos produtos, sendo o enfoque principal a criação de uma joia. Recentes pesquisas na área de design e moda enfatizam os símbolos, a emoção e o apelo visual dos produtos como um dos principais temas de projetos de design joalheiro. O trabalho a seguir pretende abordar essa área de pesquisa focando no apelo visual e emotivo como item primordial na concepção de um produto de moda.
\end{abstract}

Palavras-chave: joias, design, estética e simbolismo.

\begin{abstract}
Aesthetics and symbolism represented by a jewel are determinative factors for its choice. This article has the objective to realize an analysis of the use of these factors in new products creation, being the principal approach to creation the jewel. Recent inquiries of design and fashion areas emphasize symbols, emotion and appearance of products like one of principal design subjects. This paper intends to board this inquiry area focusing in visual and emotional appeal like primordial item in fashion products.
\end{abstract}

Keywords : jewel; design; aesthetics and symbolism. 


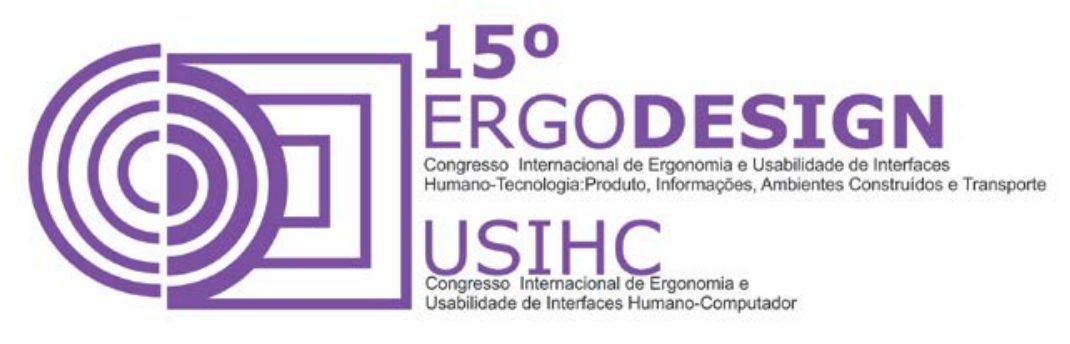

\section{INTRODUÇÃO}

As escolas de Design no Brasil, por muito tempo tiveram como objeto de estudo principal o desenvolvimento de produtos focados para a funcionalidade. Os produtos eram excessivamente técnicos com pouca preocupação estética. O desenvolvimento tecnológico e a globalização fez surgir novos produtos com características resultantes destes fenômenos, o consumidor passou a ter novas exigências em especial ás de caráter estético.

O mercado atual é um reflexo da evolução do pensamento estético e simbólico do consumidor e de sua consequente influência na indústria, onde este deseja um produto que possua qualidades de excelência técnica e de manutenção preditiva aplicada, aliados a diferenciais estéticos inovadores, expressando desta forma suas individualidades.

O objeto de estudo do presente artigo é a joia. Por sua própria natureza expressa simbolicamente valores, significados e ritos, dentro do repertório de costumes da vida urbana.

As joias, que visualmente se expressam por meio de formas e cores não podem ser reduzidas a simples ornamentos. Sua valorização é resultado de seus componentes preciosos e do status relacionado a seu uso.

A joia brasileira é um produto de destaque internacional, com design reconhecido por suas formas inovadoras, utilização de materiais e gemas diferenciadas. Isto é comprovado através dos vários concursos internacionais onde designers brasileiros possuem lugar de destaque e do sucesso de marcas brasileiras no exterior. De acordo com o Instituto Brasileiro de Gemas e Metais (2013) o Brasil é o maior produtor mundial de gemas coloridas, possui reservas de ouro calculadas em 30 mil toneladas e é responsável por 1 a $2 \%$ da produção mundial de diamantes de qualidade.

Apesar do crescimento do mercado de joias, dos cursos técnicos e de graduação, existe pouca bibliografia disponível sobre o processo de criação de uma joia. A maioria dos livros são focados em desenho de joalheria, feitio de joias artesanais e normas técnicas. O enfoque do processo de criação de uma joia possui um grande potencial de desenvolvimento.

O objetivo deste estudo é analisar o uso da estética e do simbolismo na criação de joias e com isso definir uma proposta de processo de criação focado no aspecto visual do produto. 


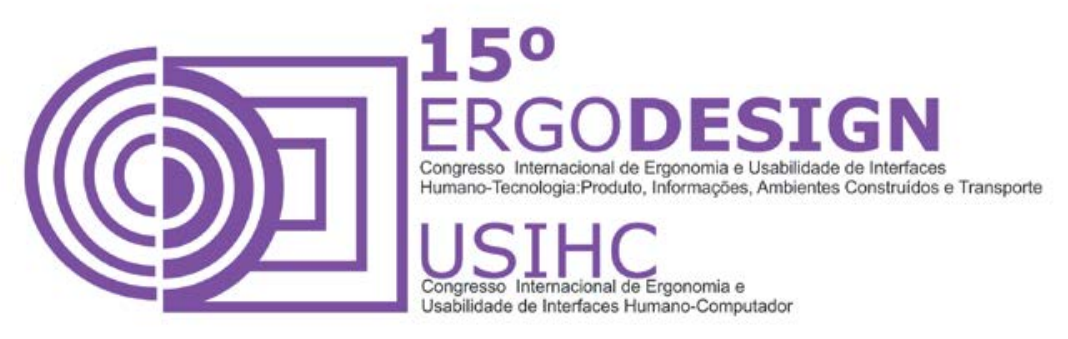

\section{A ESTÉTICA E O SIMBOLISMO}

O design pode dar formas tangíveis e permanentes sobre as ideias, o perfil, os anseios e comportamento das pessoas. A forma é um dos muitos aspectos a ser levado em conta em um projeto e não é um fenômeno isolado. Tem relação direta com as outras variáveis do produto. $\mathrm{O}$ design não pode ser classificado como uma atividade ligada apenas à arte ou à tecnologia, mas, sim, uma atividade projetual multidisciplinar que conjuga e harmoniza conhecimentos dessas duas áreas, entre muitas outras. Segundo Munari (1993) a arte e a estética são fundamentais no ofício de projetar, devendo estar presentes nos objetos e produtos de design.

É função do designer projetar produtos funcionalmente adequados, aplicando os conhecimentos técnicos e da ergonomia, mas com qualidades estéticas e simbólicas a fim de conquistar o consumidor. Esta função só será cumprida de forma eficiente se o profissional souber fazer uso simultâneo dos fatores racionais e emocionais em seus projetos. Os fatores emocionais são os primeiros a serem percebidos. Decidimos se gostamos ou não de um produto, apenas com uma exploração visual, olfativa ou auditiva, já os racionais são mais demorados, pois dependem do uso ( $\mathrm{LÖBACH}, 2001$ ). O estudo das emoções tem interessado cada vez mais aos designers, devido a sua grande importância na tomada de decisões, já que em muitos casos, é o fator primordial na escolha dos produtos; os aspectos racionais acabam ficando em segundo plano.

Para Baxter (2000) o consumidor confia no produto quando o mesmo consegue refletir a sua autoimagem e constrói a sua imagem perante os outros. Os designers fazem isso incorporando algum tipo de valor estético e simbólico nos produtos.

A estética é a primeira característica observada pelo consumidor num produto em exposição, segundo Carpes Junior (2004), contribuindo decisivamente para a venda. Na maioria das vezes a função estética determina 0 ato da compra, ao invés das funções práticas de um produto industrial, funções estas percebidas apenas a médio e longo prazo ou durante a utilização do produto (LÖBACH, 2001).

A Estética pode ser definida como a ciência das aparências captado pelos sentidos, de sua percepção pelos homens e sua importância para eles como parte de um sistema sociocultural (LÖBACH, 2001). Na verdade é a faceta de um processo, onde são estudados os aspectos estéticos do produto percebidos pelo usuário tendo como objetivo principal reconhecer e descrever os pontos perceptíveis dos objetos. Para se desenvolver produtos com excelência estética é necessário o conhecimento dos mecanismos de percepção visual, aliados à compreensão destes em conformidade com as normas socioculturais e principalmente os conceitos de valor aplicados por determinada sociedade (CARPES JUNIOR, 2004). 


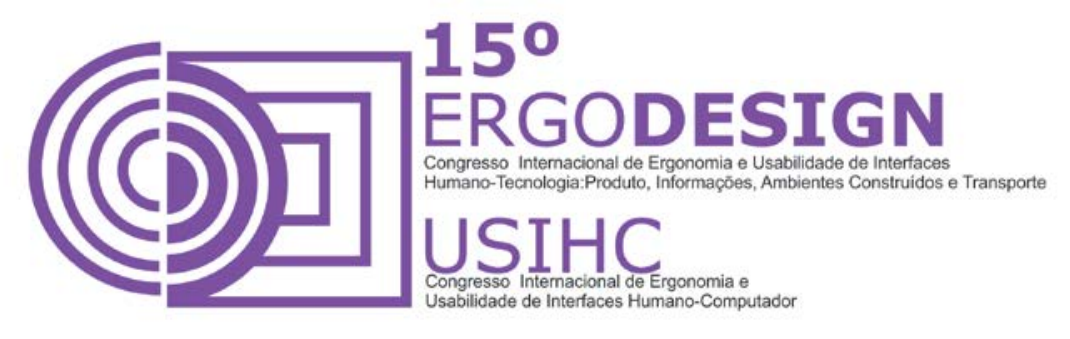

O valor estético é resultado da função estética, tendo como definição a medida do prazer estético percebido pela aparência visual do objeto ao usuário. Este não é fixo, e depende das aparências sociais, está sujeito a mudanças e é único para cada estrato social e individuo (LÖBACH, 2001).

Simbolismo do produto é a imagem transmitida pela aparência do produto, são os valores humanos associados aos produtos (BAXTER 2000).

"A linguagem é um signo mediador por excelência, pois ela carrega em si os conceitos generalizados e elaborados pela cultura humana" (REGO, 2007). Os pensamentos e atos são estruturados pelas representações simbólicas do ser humano enquanto tal tem do universo, e estas representações são manifestas nas ideias, nas comunicações e nas ações (DOMINICIANO, 2008).

Löbach (2001) comenta que o designer precisa receber ou diagnosticar as indicações precisas sobre o efeito e a importância do símbolo pretendido. A dificuldade está em encontrar um conjunto adequado de meios estéticos para produzir o efeito simbólico pretendido. A configuração visual de sua aparência é a primeira hipótese para isto. A tarefa principal do designer industrial na criação de produtos industriais com alto grau de função simbólica continua recaindo sobre a aparência formal dos produtos, principalmente com o uso dos meios estéticos. O artefato é resultado das concepções e valores resultantes da leitura do designer sobre a cultura e a sociedade a que pertence. O planejamento e a concepção dos produtos envolvem a configuração de comportamentos e a atribuição de significados aos objetos de uso cotidiano.

O ornamento serve como elemento narrativo da própria História da humanidade, o ser humano atribuiu-Ihe valor simbólico, principalmente mágico e com isso deu significado ao seu adorno. Posteriormente ao valor simbólico deu valor estético e por fim o valor material (BRAGA, 2008).

Para os empresários, a utilização dos significados simbólicos é fundamental para o sucesso comercial. O produto, para ter êxito, deve incorporar as ideias para torná-lo comercializável, e a tarefa específica do design é provocar a conjunção entre essas ideias e os meios disponíveis de produção (FORTY, 2007). O usuário considera o produto esteticamente agradável a partir do momento que percebe certos aspectos. Estes seriam de acordo com a Teoria do Gestalt: simetria, proximidade, similaridade e continuidade. Esta teoria foi criada por psicólogos alemães no início do século $X X$, consiste que a visão humana tem uma predisposição para reconhecer determinados padrões, ao olharmos um objeto pela primeira vez o nosso cérebro programa para extrair certos padrões visuais e arrumá-los em uma imagem com significado (BAXTER, 2000). 


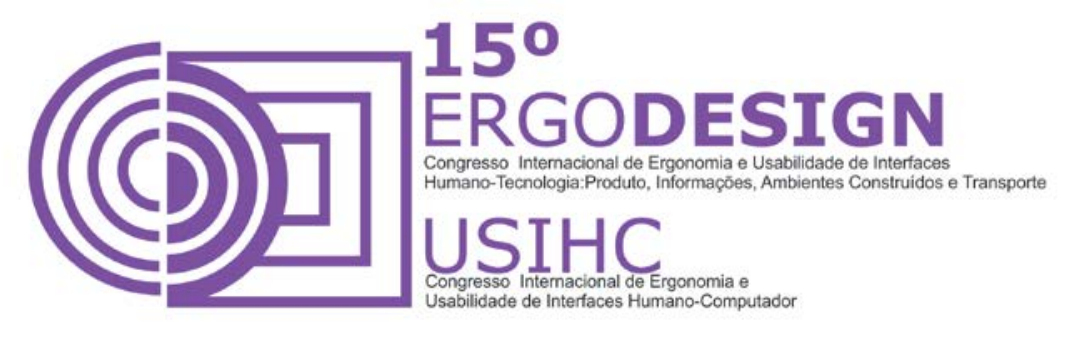

A simetria torna o foco observado mais agradável e gera o equilíbrio entre os componentes do objeto apreciado. Gera-se a proporção no todo e, normalmente, é complementado por uma padronagem capaz de ornar o objeto com elementos, formas e cores. Essas premissas observadas nos dão a sensação de harmonia, ou seja, o conjunto de todos os componentes citados capazes de atrair a atenção e a consequente sensibilização do observador BRAGA (2008).

Baxter (2000) cita em seu livro uma pesquisa realizada pelo psicólogo Daniel Berlyne sobre os objetos considerados atrativos onde foi criada uma curva de preferência para a complexidade visual (Figura 1). Os produtos considerados muito simples ou muito complexos apresentaram baixo grau de preferência, em relação aos intermediários. Enquanto que um nível intermediário apresenta alto grau de preferência, esses produtos estão classificados em um nível denominado "ótimo de complexidade", ou seja, possuem um alto grau de atratividade, esta resulta de uma combinação adequada de elementos simples e complexos com significado simbólico.

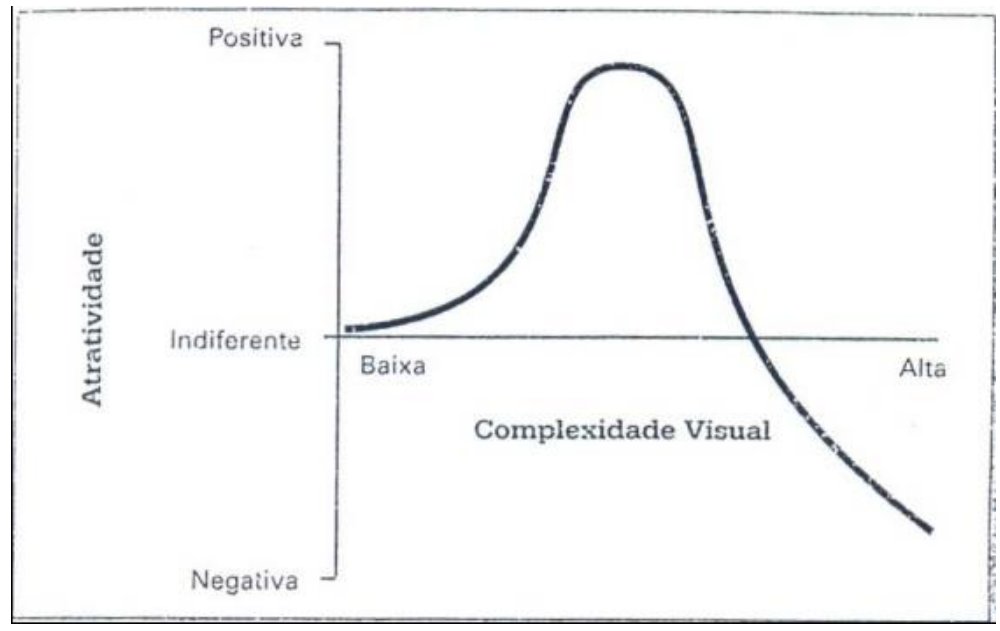

Figura1 - Modelo de Berlyne

Fonte: Baxter (2000, p. 35)

A leitura estética e simbólica de um produto pode ser comparada a uma leitura de obra de arte, a imagem possui dois aspectos diferentes - a qualidade semântica (denotativa, descritiva) e a qualidade estética (conotativa, valores que se descobrem, quer no plano de conhecimento, quer no plano da sensibilidade). Esta última depende dos ritmos, formas, espaços, cor e luz (DOMICIANO, 2008) . 


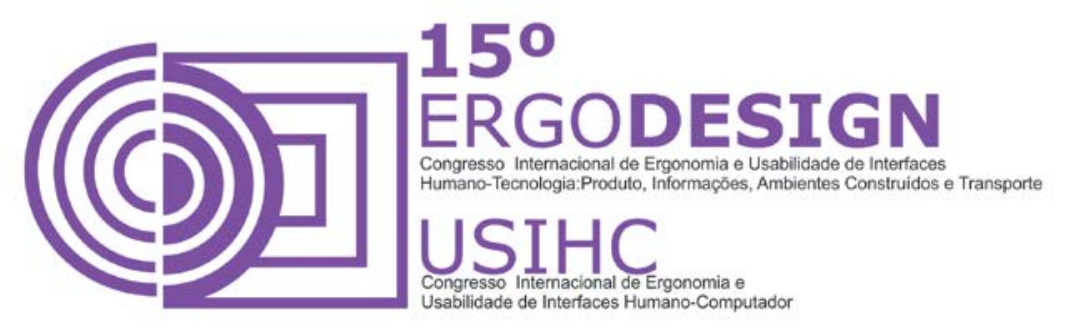

Bamonte (2005) cita o fato de a função estética muitas vezes sobrepor à funcionalidade do produto e com isso deixa de ser produto de consumo para se tornar objeto de arte onde 0 simbolismo anula a função.

Dominiciano (2008) comenta que Villafañe na busca de definir uma "teoria da imagem", fala da importância de se entender o papel da percepção, pois ela é o processo responsável pela seleção da realidade.

A percepção é a faculdade mais primária do ser humano. Através da percepção toma-se consciência de si mesmo e do mundo ao redor. Usa-se para isso as capacidades sensoriais. A princípio, interessa-nos a percepção visual, esta é um fenômeno físico, onde informações luminosas são recebidas e decodificadas num processo que envolve inúmeros partes do olho, sistema nervoso e cérebro. Nesta decodificação discernimos o grau de luminosidade, as cores, bordas, e outros fenômenos mais complexos, como profundidade, movimento e perspectiva (DOMICIANO, 2008).

\section{A JÓIA E SEU PROCESSO DE CRIAÇÃO}

Braga (2008) comenta que a palavra joia possui origem latina - jocalia - seu significado: “ coisas festivas, alegres e supérfluas". A joia é uma ornamentação com o intuito de celebrar, comemorar, enfeitar, sensibilizar, reluzir, valorizar e, também, de proteger. Em uma definição mais tradicional as joias são objetos feitos de metais nobres, pedras preciosas ou de pérolas, cujo trabalho prevalece á característica artesanal.

No decorrer do tempo a joia teve várias funções, além da de símbolo de posição social; a de função mágica do amuleto, fazendo uma ponte entre o homem e a natureza. Seja qual for sua função, elas têm representado a necessidade da representação de si mesmo e da própria vida. A joia teve sua função inicial de status e de seu valor intrínseco modificado, seu conceito tornou-se mais amplo, seu uso foi ampliado e difundido mais democraticamente. Este conceito amplia principalmente os materiais possíveis para sua fabricação, e seu diálogo com as peças do vestuário. Seus materiais preciosos se misturam a materiais naturais, resinas, plásticos e vidros.

Ao se analisar as joias, na ausência de qualquer informação imediata sobre o contexto histórico e técnico, o espectador sente o impacto da aura destes objetos, sua emanação incomparável. Nesta aura, a presença real e as imagens mágicas às quais ela remete, são ressaltadas com a mística das peças e finalmente com a análise do passado do objeto. São investidas de uma carga semântica estabelecendo uma ponte à imaginação e um convite para o observador às projeções associativas, na busca de expressões de desejos e construção de uma autoimagem. O objeto está investido de muitos significados, como, por exemplo, status. O valor material é o resultado da somatória do valor estético e simbólico, pois o objeto estimado torna-se precioso.

O designer de moda usa intensivamente os fatores emocionais na formulação de novas configurações para os produtos e ao mesmo tempo em que cria o produto, planeja sua materialização, para o mesmo ser especificado dentro de uma realidade produtiva (BRAGA, 2008). 


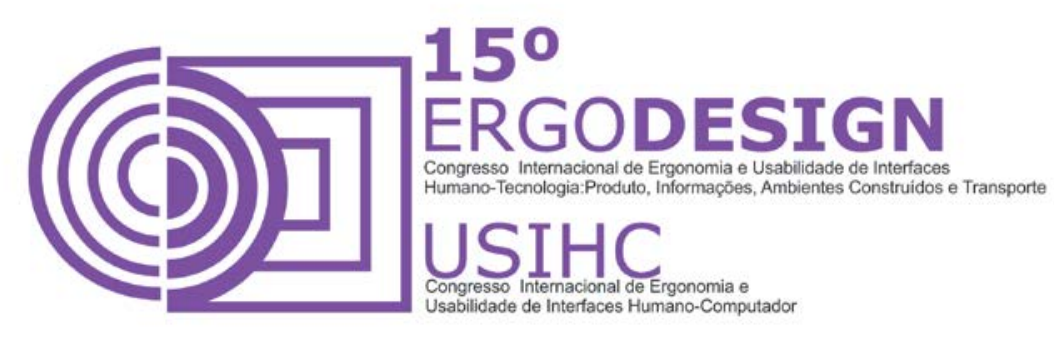

Todo o material empregado tem seu valor simbólico na construção de uma peça, independente da preciosidade dele.

Preuss (2003) cita que a joalheria evoluiu muito nos últimos anos e hoje utiliza das novas tecnologias para ter sua importância no mercado. No Brasil é um mercado em crescimento e tem representado o design brasileiro no cenário internacional. Ela tem seu desenvolvimento junto com a evolução da tecnologia e junto com as mudanças na arte, moda, sociedade e culturas. A descoberta das gemas brasileiras e suas especificidades representaram um rompimento com a joia tradicional, e uma nova dimensão de fantasia como se observa hoje, nas novas coleções de joalherias brasileiras como a Vancox (Figura 2).

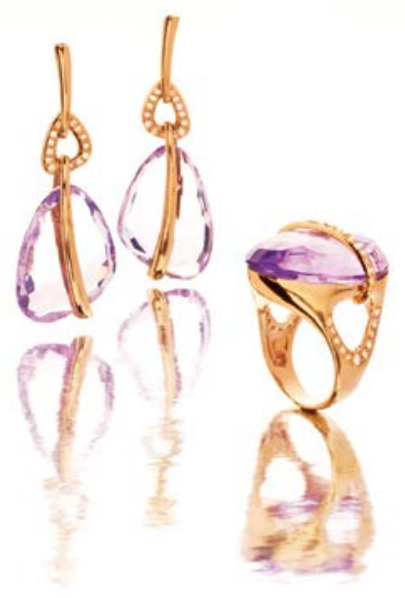

Figura 2 - Anel e Brinco Vancox

Fonte: www.vancox.com.br

O poder criativo pode estar relacionado com um novo tipo de liga e de usinagem para o metal, no qual podem existir diversas variantes. Outras vezes, esse poder criativo pode estar vinculado a pedras preciosas, onde o tipo de lapidação e/ou cravação pode dar um novo aspecto, uma nova vida para a joia (REBELLO, 2007).

De acordo com Grunow (2007), o designer de joias Antônio Bernardo, possui em seu escritório de criação esculturas de papel, arame e massa de modelar, feitas a mão (Figura 3), pois ele as utiliza no processo de criação das novas peças, a fim de transformar palavras, matemática e temas inspirados nas artes, na natureza e no comportamento humano, em joias. As descontraídas esculturas substituem os metais e, assim, surgem como diálogo entre ideia e matéria. São, portanto, simbolicamente o retrato do domínio técnico e da liberdade criativa do designer. 

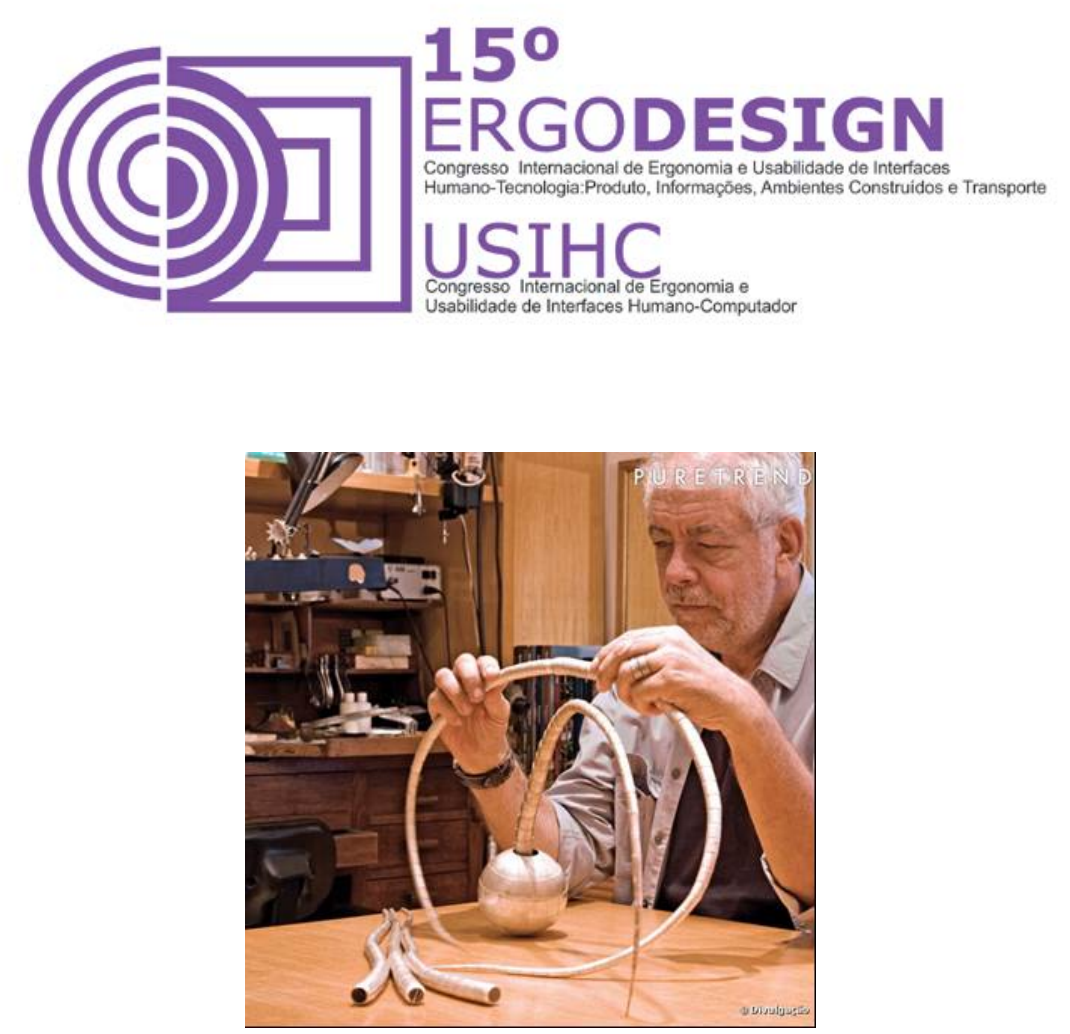

Figura 3 - Designer Antônio Bernardo manuseando sua escultura.

Fonte: www.puretrend.com.br

A fase inicial de criação é a inspiração e a escolha de um tema para guiar as fases seguintes, como por exemplo, a forma das peças a serem produzidas. Geralmente cada coleção é baseada num tema e a partir deste são criados minicoleções. Na fase de observação, coleta de imagens e informações algumas características podem vir a originar a base de uma joia, sendo criado um esboço da peça a mão livre ou por um software específico. Toda a informação levantada para a criação do produto pode vir a expor o designer a um grande número de ideias projetuais (REBELLO, 2007).

Vários esboços e rascunhos são feitos, os melhores são aproveitados para serem prototipados, mas nada é descartado, pois os esboços não aproveitados podem conter traços e ideias para servirem de base a outros componentes.

Rebello (2007) comenta que a competitividade do mercado de joias criou uma demanda por peças com estilo e personalidade e com isso abriu as portas para a criatividade e o uso de novos materiais e técnicas na confecção das mesmas. Ao projetar e desenhar, o designer deve criar desenhos o mais próximo possível da realidade com detalhes bem representados, uma perspectiva e vista mostrando os detalhes, dimensões, acabamentos e colocações de pedras. Este cuidado com os detalhes do desenho é fundamental, pois o ourives irá executar a peça de acordo com a representação gráfica da peça criada.

No mercado de pequena produção de joias ou de peças exclusivas, a criação e os desenhos são processos essencialmente manuais e artísticos. O fato de serem peças elaboradas e únicas criam um valor agregado ao produto.

A joalheria ainda utiliza muito os processos manuais na sua fabricação, mas existem novas tecnologias para auxiliar se não em todo o processo, mas pelo menos em uma parte para alcançar uma maior precisão no projeto e na fabricação da peça piloto (WINKLER, 2013). 


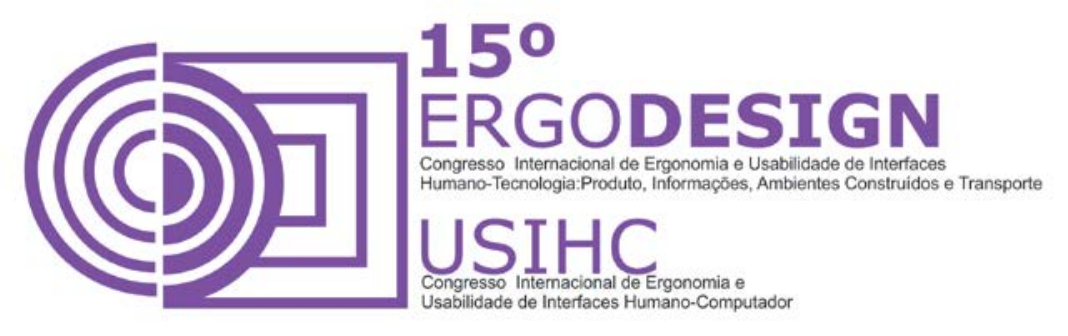

\section{MODELO PROPOSTO}

A joia é um produto cujo maior apelo de venda é sua estética e simbolismo transmitido ao consumidor. Por ser um produto cuja principal função é de adorno do usuário, ela apresenta as mais diversas formas, variações de modelos e inúmeros e diferentes materiais como componentes. Está ligada diretamente com as tendências de comportamento e de estilo vigentes no mercado. Esta influência pode não ser tão aparente como no vestuário, mas não deixa de existir, pois na primeira etapa de levantamento de informações, imagens, enfim de material de inspiração e de apoio para a criação, as macrotendências de comportamento e as tendências de moda vigentes na época irão exercer grande influência de decisão do design final do produto.

Este estudo propõe um processo de criação do produto joia focado no aspecto visual, com ênfase na função estética e simbólica (Figura 4). Vale lembrar que a proposta não é de desenvolver um processo de desenvolvimento da joia, pois o desenvolvimento será de acordo com a tecnologia e as ferramentas disponíveis.

A primeira etapa no processo de criação é a análise do público alvo do produto e de seu mercado de atuação. A segmentação neste caso deve ser feita de acordo com o estilo de vida, estilo de comportamento e aspirações do consumidor. Deve ser definido o valor estético do produto de acordo com o período de tempo da sua comercialização, ou seja, da estação. Esta etapa deve ser desenvolvida tendo como ferramenta de apoio uma pesquisa de mercado.

O valor estético depende das aparências sociais, está sujeito a constantes mudanças e é específico de cada estrato social. É a medida do prazer estético proporcionado pela aparência visual do produto industrial no usuário, não é um número absoluto, ou uma regra definida e imutável, na verdade este pode ser definido como várias características visuais consideradas esteticamente agradáveis para certo público alvo, características estas dotadas além do valor estético, mas também de valor simbólico. A principal função da estética e do simbolismo no projeto é a de criar um elo de ligação e de empatia com seu usuário para definir a escolha de compra do produto.

No valor estético de uma joia está inserido o tipo de metal a ser utilizado, o uso ou não das gemas, o tipo de gemas, as cores, a forma e o estilo do produto.

Após a definição do valor estético percebido pelo público alvo da empresa, o design do produto, ou seja, sua configuração será desenvolvida de acordo com o valor estético definido com a influência das tendências de moda previstas e de acordo com a tecnologia de produção disponível na empresa.

Este simples processo de criação é baseado no processo de comunicação estética desenvolvido por Löbach (2001). A criação da joia se assimila ao desenvolvimento de uma coleção de vestuário onde o aspecto visual e a empatia gerada pelo produto irá determinar sua compra. A pesquisa de mercado e do comportamento do consumidor exerce influência direta no projeto como um todo. 

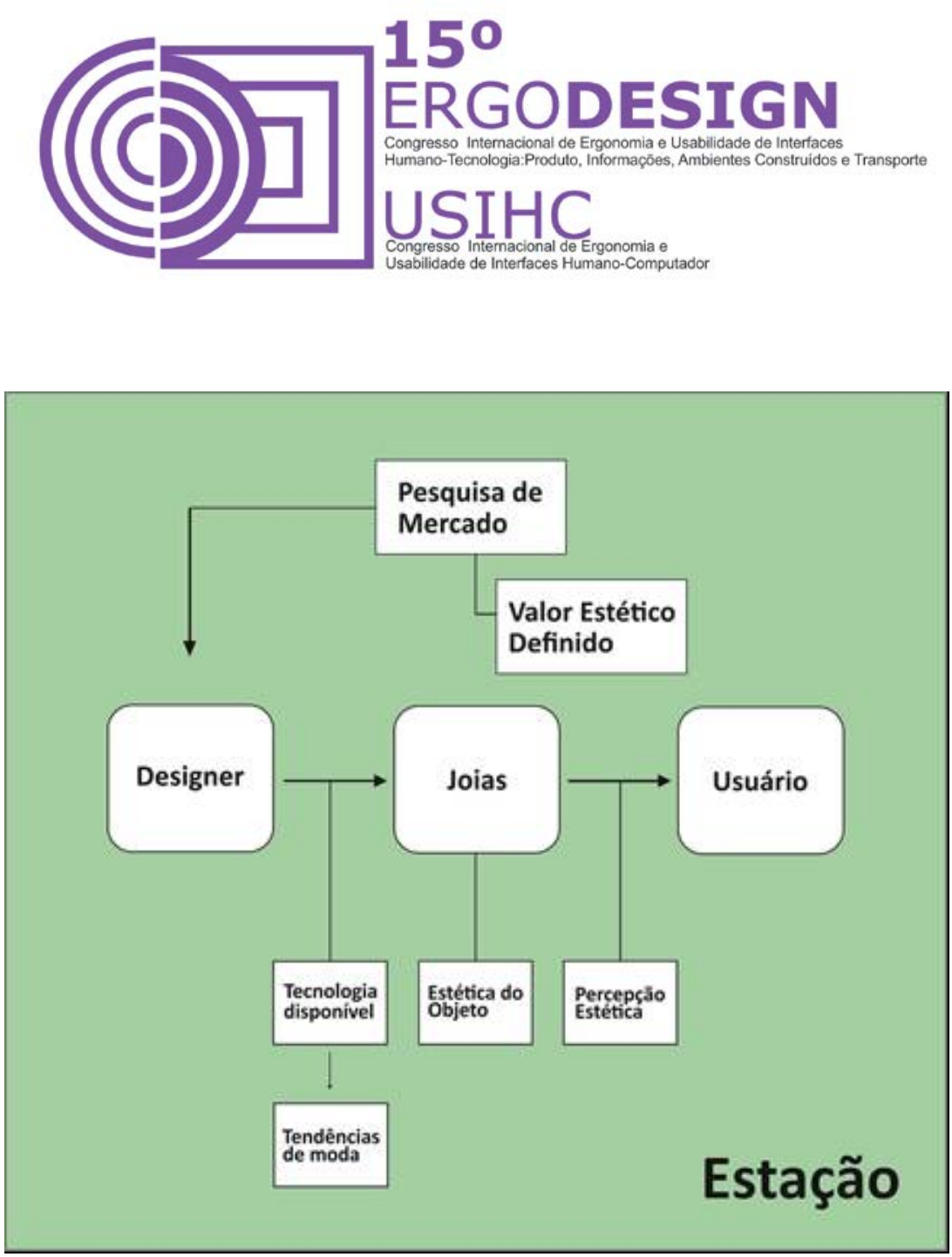

Figura 4 : Esquema do modelo de criação proposto

\section{CONCLUSÃO}

A estética é o primeiro item observado pelo usuário e contribui para a decisão de compra, mas não é mais importante do que a funcionalidade. A estética (forma) e função estão em pé de igualdade, um bom projeto de produto deve ter uma relação harmoniosa de ambas. A estética garante a atratividade do produto e a funcionalidade à consistência dele.

A joia é um produto do mercado de moda, onde a estética e o simbolismo da peça são fatores decisivos para a venda do produto. O design brasileiro no mercado de joias é amplamente reconhecido no mercado internacional, seja pelo sucesso de joalherias brasileiras ou dos concursos onde muitos brasileiros apresentam lugar de destaque.

Apesar deste crescimento do mercado e da demanda de profissionais no setor, existem poucas obras literárias abordando o ensino de design de joias. O estudo apresentado foi efetuado através de levantamento bibliográfico. O resultado foi a proposta um modelo de criação de joias enfatizando o aspecto visual do produto de acordo com os valores estéticos e simbólicos percebidos pelo consumidor. Este simples modelo deve ser aperfeiçoado e testado. O design de joias apresenta uma grande demanda de estudos na área para aprimorar e promover o crescimento sustentado do 


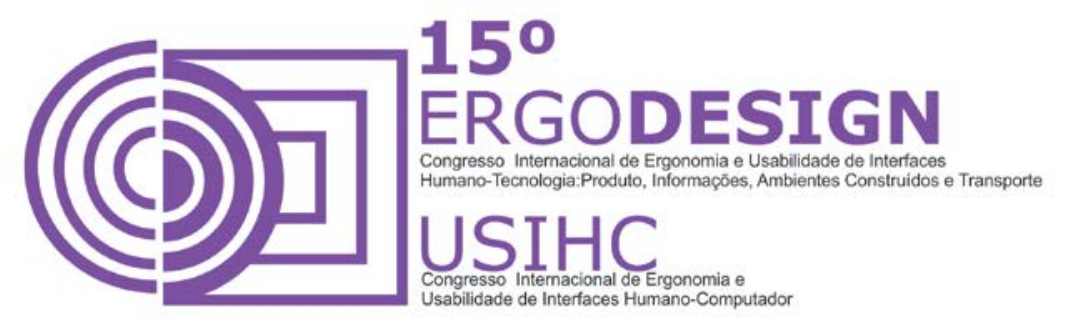

mercado. Para isto ocorrer além de incentivos governamentais na área, a rica indústria joalheira deve investir no desenvolvimento do design brasileiro como diferencial competitivo e amadurecimento do mercado de joias no Brasil.

\section{REFERÊNCIAS BIBLIOGRÁFICAS}

BAMONTE, Joedy Luciana Barros Martins. Legado: gestações da arte contemporânea. Leituras de imagens e contextualizações do feminismo na cultura e na criação plástica.. Tese (doutorado) Universidade de São Paulo, Curso de Pós-Graduação em Ciências da Comunicação, 2005.

BAXTER, Mike. Projeto de Produto: guia prático para o desenvolvimento de novos produtos. São Paulo: Edgard Blücher, 2000.

BRAGA, João. Reflexões sobre moda, volume III. São Paulo: Editora Anhembi Morumbi, 2008.

CARPES JUNIOR, Widomar Perreira. Projeto para estética: Despertando a atração do consumidor. Disponível em: <http://producaoonline.org.br/rpo/article/view/299/401>. Acesso em : 10 de agosto de 2014.

DOMICIANO , Cassia Leticia Carrara . Título: Livros Infantis Sem Texto: Dos pré-livros aos livros ilustrados. Tese (doutorado). Universidade do Minho, Curso de Pós-Graduação em Comunicação Visual e Expressão Plástica, 2008.

FORTY, Adrian. Objetos de Desejo- Design e Sociedade desde 1750 - São Paulo: Cosac Naify, 2007.

GRUNOW, Evelise. Antonio Bernardo - Rio de Janeiro: Viana e Mosley Editora, 2007.

IBGM. Estatísticas de Exportação do Setor de Gemas e Jóias 2013. Disponível em: <http://www.ibgm.com.br/info_estatisticas_avancada.php?id=135\&secao=exporta\%e7\%e3o. Acesso em : 10 de agosto de 2014.

LÖBACH, Bernard. Design Industrial. Base para a configuração dos produtos industriais. Rio de Janeiro: Editora Edgard Blücher, 2001.

MUNARI, Bruno. A Arte como Ofício. Lisboa: Editorial Presença, 1993.

PREUSS, Luciana. A Joia com grandes gemas - um ícone americano no Brasil - "The cocktail rings". Dissertação (mestrado). Pontifícia Universidade Católica do Rio de Janeiro, Curso de Pós-Graduação em Design, 2003.

REBELLO, Luiza Helena Boueri - A Produção de Jóias e o Design. Disponível em: <http://www.univercidade.br/pesqcient/pdf/2007/tec_producao.pdf> Acesso em 10 maio 2014.

REGO, Teresa Cristina. Vygotsky - Uma Perspectiva Histórico-Cultural da Educação. Petrópolis: Vozes, 2007. 


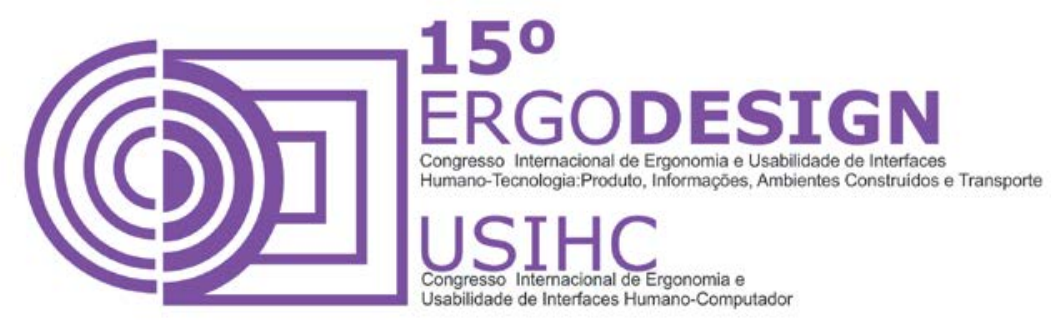

WINKLER, Camila Lucchesi. Contribuição da compreensão dos significados e respostas emocionais para os processos de projeto do design estratégico. Dissertação (mestrado). Universidade do Vale do Rio Sinos, Curso de Pós-Graduação em Design, 2013. 